\title{
NEONATAL INTENSIVE CARE NURSES ATTITUDE TOWARDS EUTHANASIA IN ISRAEL IS DETERMINATE BY PERSONAL VALUES MORE THAN THE SITUATION- A NATIONAL BASED STUDY
}

\author{
S. Dombe ${ }^{1}$, N. Tabak ${ }^{2}$, S. Coton ${ }^{2}$, B. Barzilay ${ }^{1,3}$ \\ ${ }^{I}$ Neonatal Intensive Care Unit, Assaf Harofeh Medical Center, Zerifin, ${ }^{2}$ The Stanley Stayer School of Health \\ Professions, ${ }^{3}$ Sackler Faculty of Medicine, Tel Aviv University, Tel Aviv, Israel
}

Background and aims: The medical progress treating infants increase survival, sometimes in the expense of increasing neuro-developmental morbidity. As care givers we believe that sometimes death is not the worst outcome. There is a lot of debate what will be the best way to treat (or not to treat) babies with poor prognosis. It is important to identify which factors affects the decision whether to treat or not those infants with bad prognosis. After identifying those factors we were interested to see whether intrinsic factors (values) or extrinsic factors (the legal situation) will determinate the nurse support of euthanasia in the individual case.

Methods: 140 NICU nurses from different units in Israel completed a questionnaire regarding their attitude towards treating infants carrying poor prognostic conditions. The questionnaire was validated previously. It included intrinsic and extrinsic factors that may affect the decision for the best way to treat those infants.

Results: The intrinsic factors (like religion, believes towards life and death issues, etc.) were by far more important in the nurses attitudes towards treating those neonates compared to extrinsic factors (like the legal situation, parent request, and DNR written order).

Conclusion: These findings that the individual believes towards life and death are more important than the legal situation when considering euthanasia may help us understand the differences between countries and societies towards infants' euthanasia. 